\title{
Comparative analysis of underfloor wheel lathes with monolithic and bolted structure in terms of static and dynamic properties based on the results of FEM analyzes
}

\author{
$T$. Pochopień, $K$. Lehrich, and $J$. Śliwka \\ Department of Machine Technology, Faculty of Mechanical Engineering, Silesian University of \\ Technology, Poland
}

\begin{abstract}
The subject of the research was Underfloor Wheel Lathes designed to regenerate the profiles of the running wheels and brake discs of heavy rail vehicles without removing the wheelsets. These machines can also be used to regenerate wheel sets in trolleys dismantled from vehicles or the wheel sets themselves. The machine tools operate in a pass-through system. Two machine tools differing in the structure of the supporting system were tested: monolithic and folding. Conclusions are based on the results of the FEA simulation. They concerned the influence of the type of supporting structure and connection between the bodies on the static stiffness, forms of vibrations and dynamic stiffness of machine tools.
\end{abstract}

\section{Introduction}

Underfloor wheel lathes are used in the railway industry. They allow re-profiling (rolling) of the wheel profile of some railway vehicles. Rolling the wheels of railway vehicles allows the rolling stock to be kept in good technical condition (the operation is required after obtaining a mileage of approximately $500,000 \mathrm{~km}$ ) and has a direct impact on the comfort of travel in passenger vehicles (noise, knocks, etc.).

Manufacturers who want to gain new customers must constantly improve the quality and attractiveness of their products. As far as machine tool manufacturers are concerned, this most often refers to ensuring the desired static stiffness, which corresponds directly with machining accuracy and machine tool performance $[1,2]$. The higher the static stiffness, the higher the dimensional and shape accuracy can be obtained. Higher machining parameters can also be used, which allows to increase the machining efficiency. Dynamic stiffness and the ability to dampen vibrations are also important. Therefore, the question arises what the supporting structure of the machine tool should be like. Should it be a steel structure welded and bolted from modules, a cast iron structure bolted from modules, or a monolithic cast iron structure? Some manufacturers also decide to use a polymer concrete cast structure or a hybrid one, i.e. a steel structure filled with polymer concrete $[3,4,5,6]$. The choice depends largely on the type of machine tool, its intended use and the size of it. It also depends on the manufacturing technology available to the manufacturer. 
The subject of this study is the analysis of two variants of the structure of the bearing system of an underfloor wheel lathe intended for machining of wheelsets.

This machine tool is classified as heavy machine tool. In this case, the supporting structure of the machine tool is most often made of cast iron, but there are manufacturers who choose steel supporting structures. The advantages of cast iron structures in relation to steel structures are much better vibrations damping, high dimensional stability and the possibility of making geometrically very complex bodies. Therefore, assuming that the cast iron supporting structure will be chosen, the question remains whether it should be a structure combined with bolted bodies or a monolithic one. This question was the reason for dealing with the topic of this study.

Two machine tools from the same manufacturer, of the same size and purpose, were taken into account. They differ in their supporting structure in such a way that one of them is a structure built on the basis of cast iron bodies, constituting a kind of modules of the supporting structure bolted together. The other one is a monolithic cast iron structure. It is certainly easier and cheaper to cast smaller bodies, but the bodies must be joined together, which may reduce the stiffness of such a structure in relation to the monolithic one. Therefore, FEM simulation tests of both load-bearing structures were carried out in terms of the assessment of static stiffness, frequency and mode of natural vibrations and response to harmonic excitation.

Static and dynamic tests allow to identify the deformations of the main components of the machine tool, and thus to determine their impact on the accuracy and efficiency of machining (maintaining dimensional tolerances, the ability to fall into vibrations and determining the stable machining band).

\section{Research subject}

The subject of the research were two-support underfloor wheel lathes for the regeneration of road wheel profiles and brake discs of heavy rail vehicles without the need to disassemble the wheelsets (Fig. 1). These machine tools can also be used to regenerate wheelsets in bogies dismounted from vehicles or the wheelsets themselves. Machine tools work in a through-feed system. 


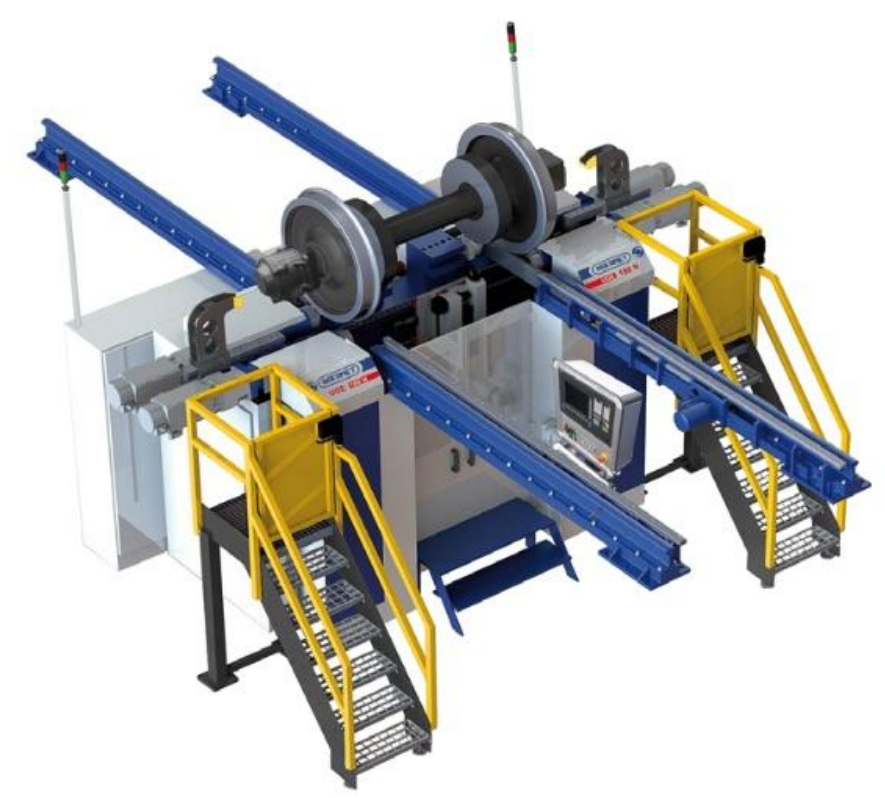

Fig. 1. UGE $180 \mathrm{~N}$ underfloor wheel lathe - allowable pressure of a single axis: 18 tons - monolithic supporting structure.

\section{Model description}

The CAD models of machine tools, developed by the designers, were modified in order to simplify them to a form that allows for FEM analyzes. For this purpose, small holes, chamfers and rounding's, which were irrelevant in the context of the formulated purpose of the analysis, were removed. The discretization of the model was performed using finite elements of the HEXA and TETRA type, with the predominance of the former. The obtained form of the mesh is shown in Fig. 2. This drawing also lists the number of nodes and finite elements. These values are comparable for both lathe models. 
a)

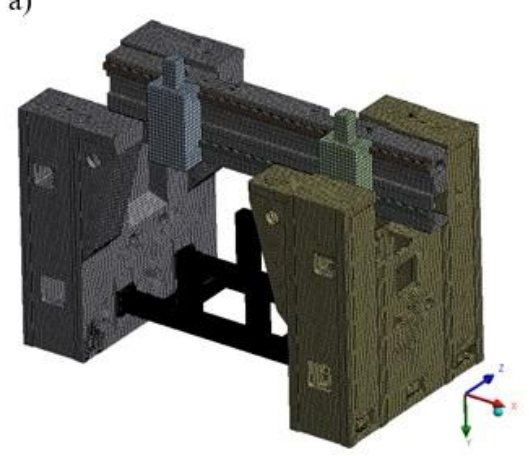

b)

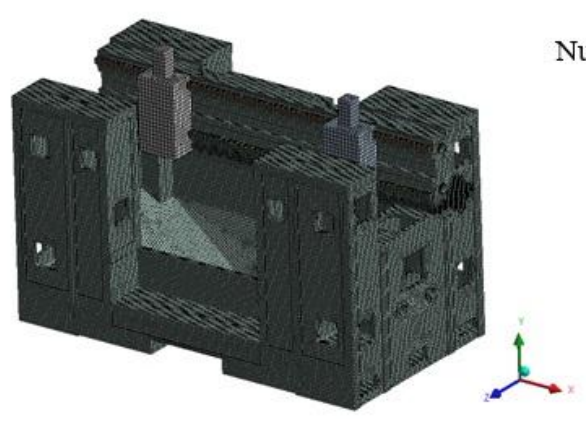

Number of finite elements: 334699

Number of nodes: 1348480

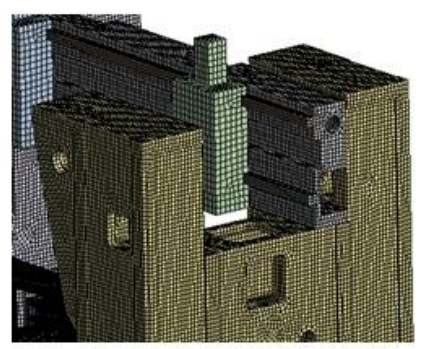

Number of finite elements: 344886

Number of nodes: 1338187

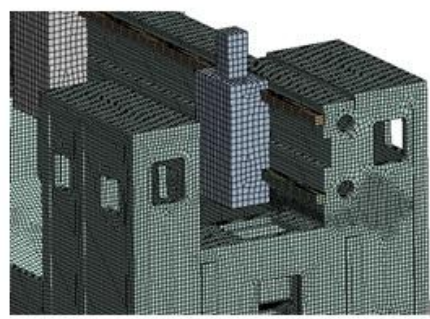

Fig. 2. Discrete models of underfloor wheel lathes with the structure: a) bolted, b) monolithic.

The boundary conditions were adopted in such a way that they corresponded to the actual state of support and load of the machine tools (Fig. 3). The same position of the carriages and their load were assumed for both machine tools. For the tests of static stiffness, the action of a constant force was assumed independently in each of the directions. This force was applied at the end of one of the slide supports, and all degrees of freedom were taken at the places where the machine tools were attached to the foundation.

Due to the adopted method of simplifying the model in the form of symmetry, another method of loading it was adopted (Fig. 5). The method of loading in this case reflected the actual load of the supporting structure better, when both carriages work simultaneously and their load is comparable. Due to the adopted assumptions, it was not possible to compare the simulation results with those obtained earlier for the entire machine tool with the load of only one carriage. 
a)
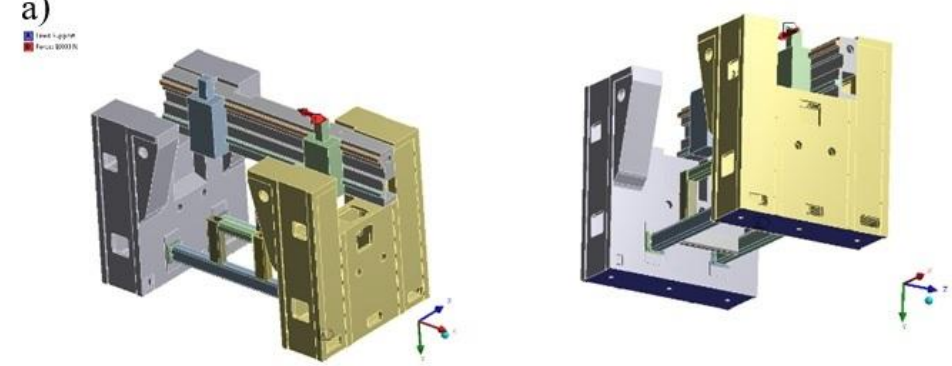

b)
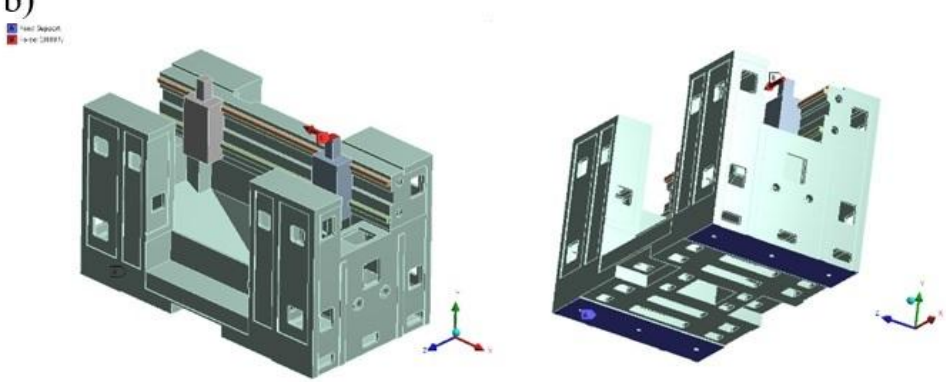

Fig. 3. Boundary conditions adopted for simulation tests of lathes with the structure: a) bolted, b) monolithic.
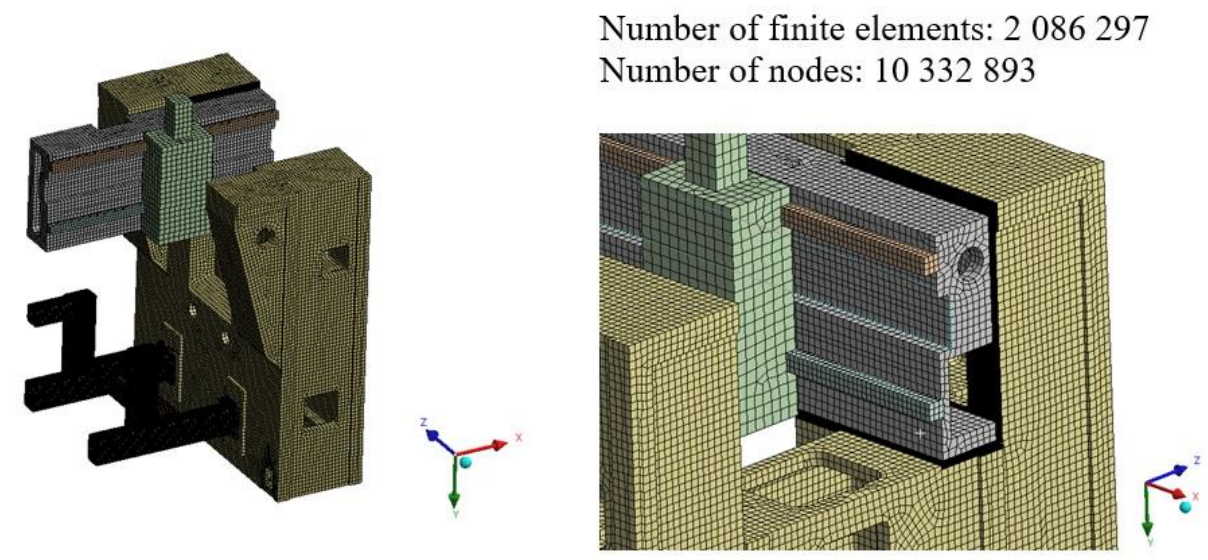

Fig. 4. Discrete model of an underfloor wheel lathe with a bolted structure for the analysis of the influence of beam and stand connection on static stiffness.

Therefore, additional analyzes were carried out for the model identical in terms of geometry and loads, assuming a rigid connection between the carriage beam and the stands. The analyzes were also repeated for a machine tool model with a monolithic structure, with similar assumptions. The obtained results provide additional information on the rigidity of the machine tool. On the contact surfaces of the carriage beam with the stands non-linear contact was assumed, and the pretension appropriate for the assumed bolt diameters and strength class was applied to the elements simulating bolts (Fig. 6). 


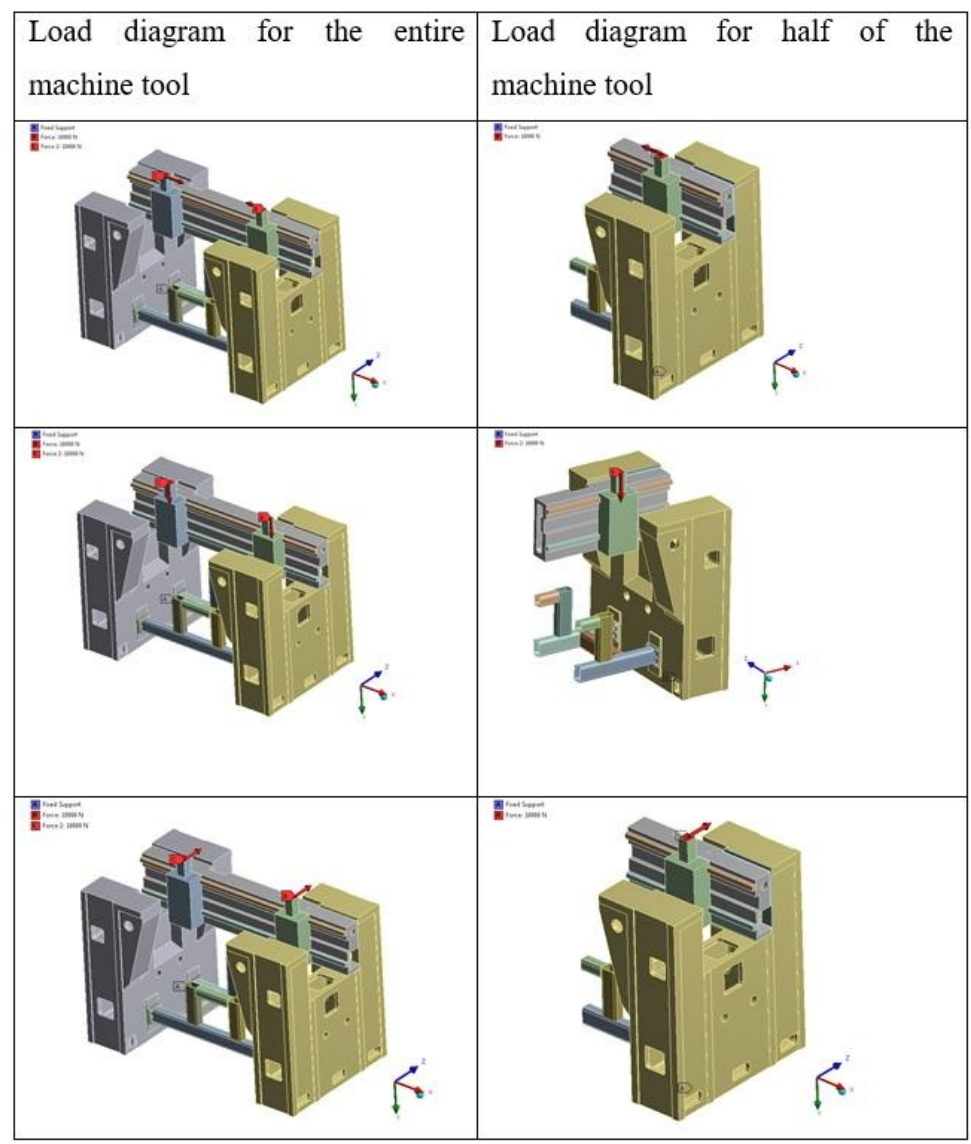

Fig. 5. Model loading for static stiffness analysis taking into account the non-linear connection in the contact between the carriage beam and the stands.

The simulations of the response to the harmonic excitation took into account the models of the entire machine tools and the rigid contact between the bodies of the bolted lathe. This is due to the limitations of the software to simulate models with only linear contacts. In the models, both carriages were loaded simultaneously in the same directions, which corresponded to the actual load of the machine tools. 


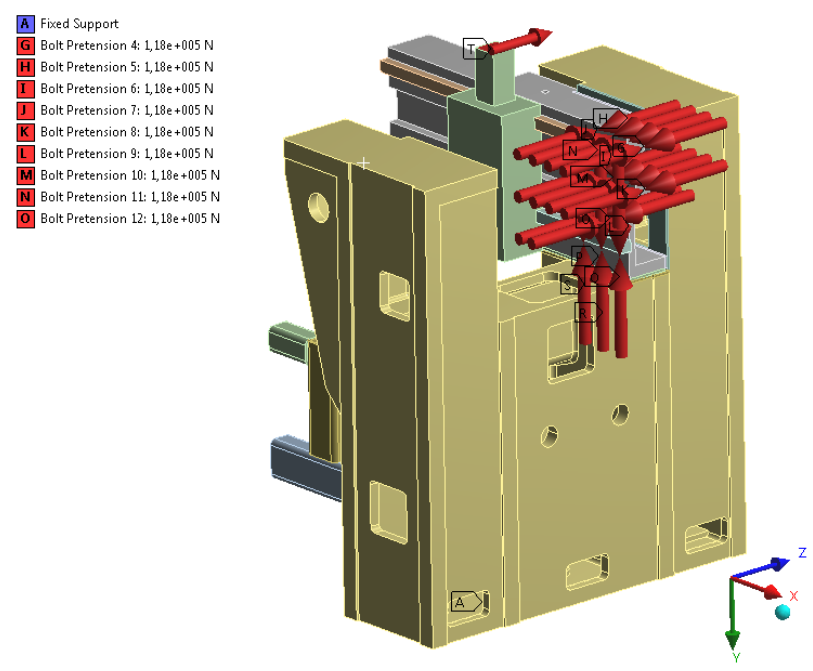

Fig. 6. Bolt connection between the support beam and the stand.

\section{Results of simulation tests}

On the basis of the obtained results, the following conclusions were formulated regarding the influence of the type of the supporting structure and the connection between the bodies on the static stiffness, vibration modes and the dynamic stiffness of machine tools.

1) The monolithic load-bearing structure is characterized by higher static stiffness in all directions. This stiffness is higher in relation to the supporting structure twisted respectively in the $\mathrm{X}$ direction by about $28 \%$, in the $\mathrm{Y}$ direction by about $15 \%$ and in the $\mathrm{Z}$ direction by about $7 \%$. Conclusions were formulated for the load of a single carriage.

2) Much higher values of static stiffness indices in the $Y$ direction result from the design of the bodies, but also from the initially adopted assumptions regarding the carriage and slider with a perfectly rigid connection on the guides.

3) The static stiffness for a bolted structure is probably overestimated, which results from the assumptions adopted at this stage of the research, concerning the ideally stiff connection between the bodies. 


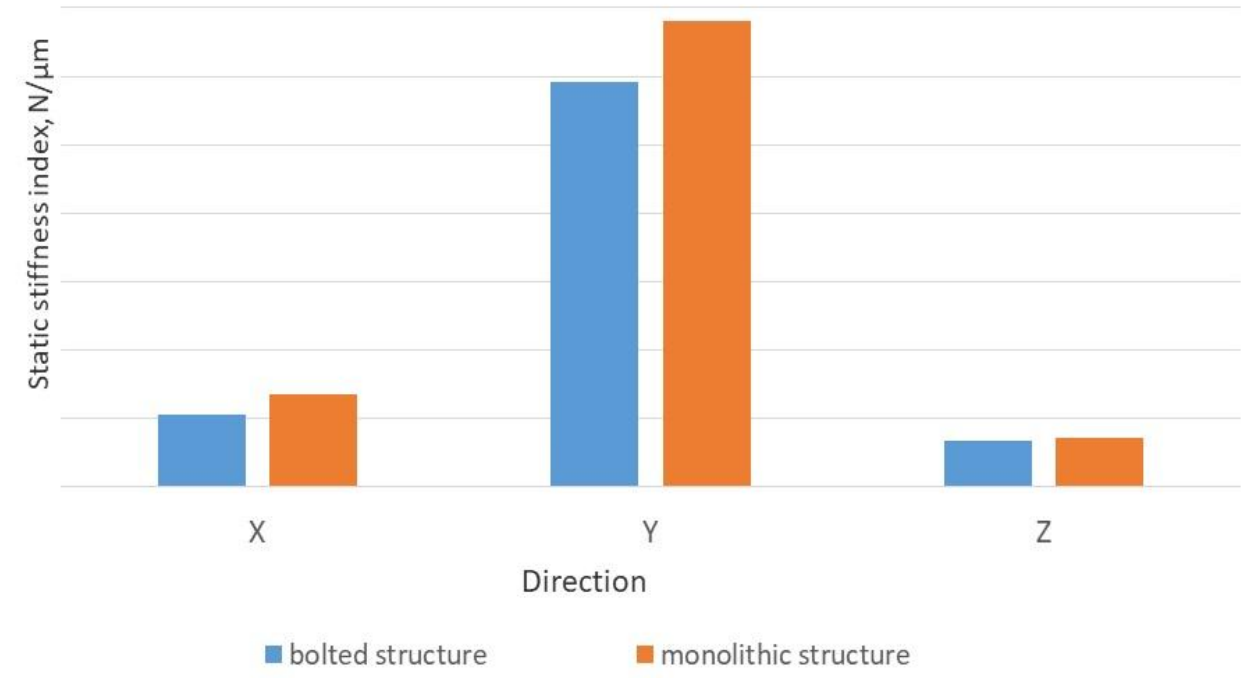

Fig. 7. Comparison of the static stiffness indices of a bolted and monolithic supporting structure for the load of one carriage.

4) Of course, taking into account the simultaneous load of both carriages gives a different static stiffness of the machine tools compared to the analysis with the load of one carriage. Taking into account the non-linear contact in the beam-to-stand connection in the bolted lathe model causes a decrease in static stiffness in the $\mathrm{X}$ direction by about $1 \%$, in the $\mathrm{Y}$ direction by about $18 \%$, and in the $\mathrm{Z}$ direction by about $10 \%$.

5) Comparison of the results of the analysis of the monolithic and bolted structures with the non-linear contact shows that the stiffness of the monolithic structure is higher by approx. $12 \%$ in the $\mathrm{X}$ direction, by approx. $63 \%$ in the $\mathrm{Y}$ direction and approx. $33 \%$ in the $\mathrm{Z}$ direction, respectively. 
a)

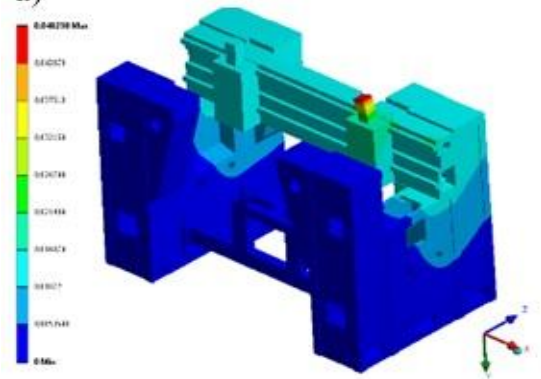

c)

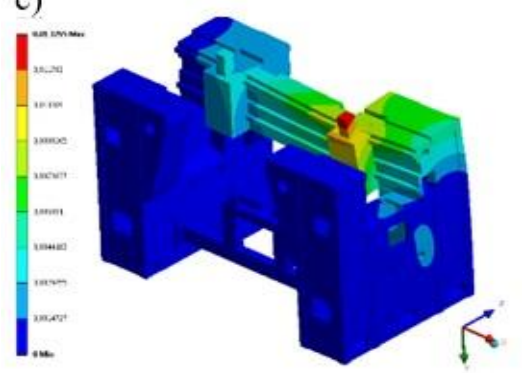

e)

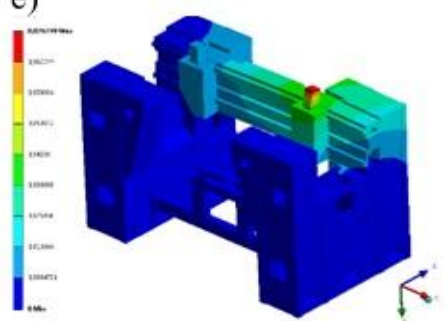

b)

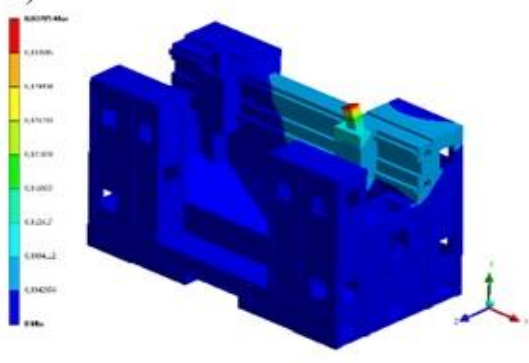

d)

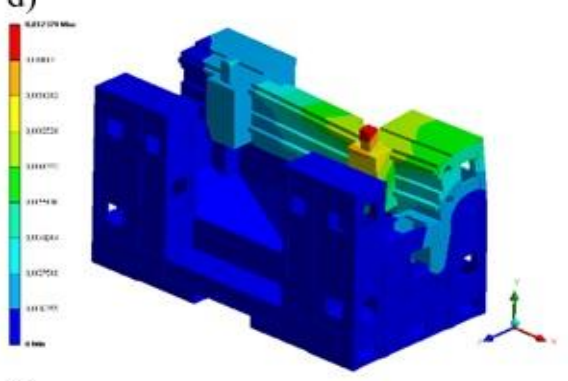

f)

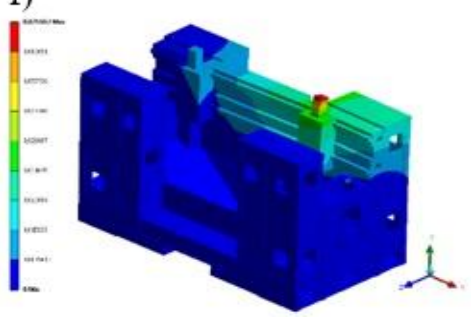

Fig. 8. List of displacements in both structures under the load of one of the sliders with a constant force.

6) A direct comparison of the natural frequencies shows higher frequencies, from about $20 \%$ to $49 \%$ (Fig. 11) for monolithic construction. However, in order to compare the natural frequencies, one should also take into account the modes of vibration, as shown in Fig. 12. Such a comparison shows an increase in natural frequency from about $8.5 \%$ to $32 \%$ for similar modes of vibration.

7) The significantly higher values of static stiffness indices and natural frequencies are the result of a different structure of the supporting structure and speak for a monolithic solution. The consideration of contact joints in the case of a bolted structure should further worsen these properties.

8) The analysis of the response to harmonic excitation was performed assuming the action of a constant force on each of the sliders, independently for the $\mathrm{X}, \mathrm{Y}$ and $\mathrm{Z}$ directions. The analyzes were performed for the dominant frequency. In the case of a lathe with a monolithic structure, it was the first natural frequency. For a lathe with a bolted structure, this frequency turned out to be the second natural frequency. For each of the lathes, based on the dominant frequency, the structure damping factor $\beta$ was calculated $[7,8$, 9]. Comparison of the results of the conducted analyzes (Fig. 12) indicates better properties of a lathe with a monolithic structure. Apart from the excitation in the Y direction, where the vibration amplitudes are comparable, the amplitude of the system response is much smaller in the case of a lathe with a monolithic structure, thus its dynamic stiffness is higher. 


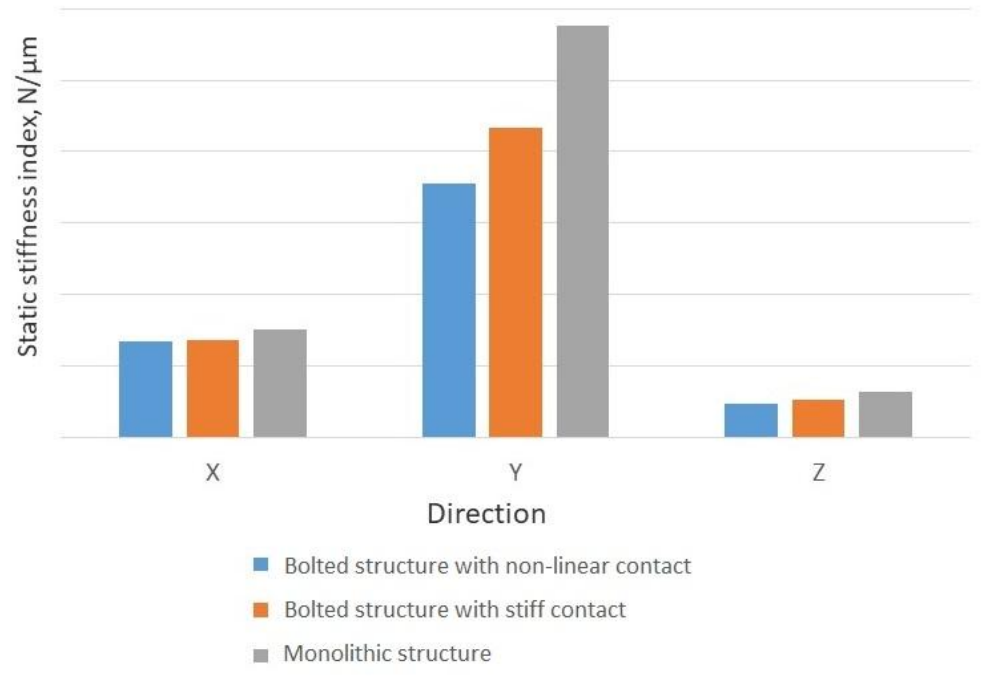

Fig. 9. Comparison of the static stiffness indices of the bolted and monolithic supporting structure taking into account half of the machine tool model (simultaneous loading of two carriages).

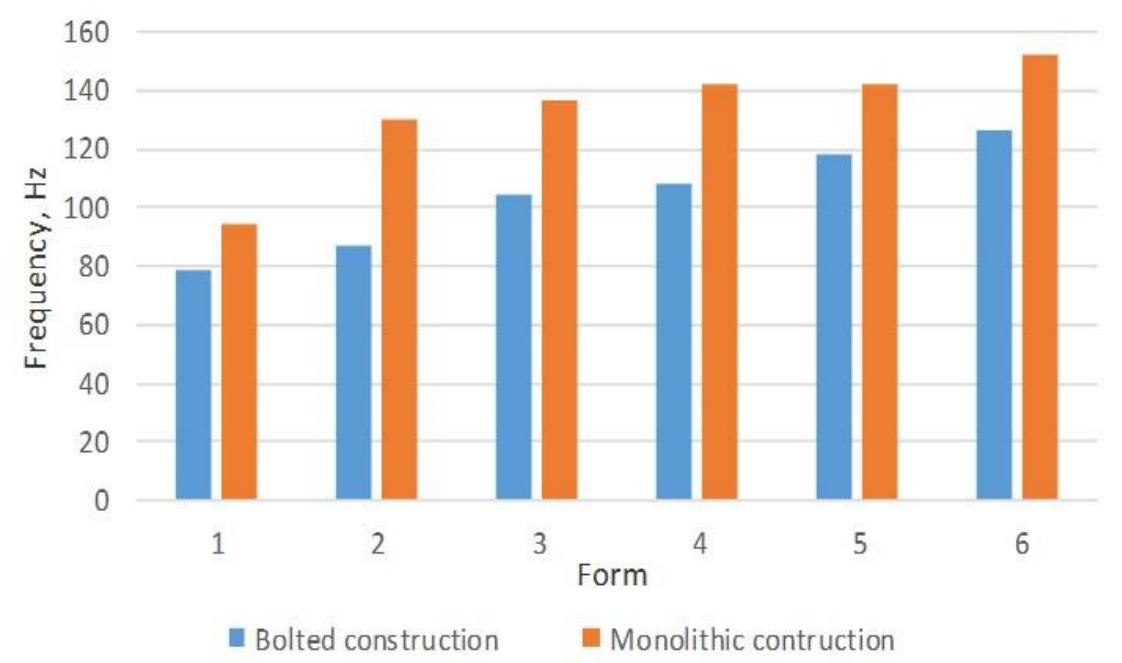

Fig. 10. Comparison of the natural frequencies of a bolted and monolithic support structure.

In both cases, regardless of the direction of excitation, the highest amplitude of vibrations was recorded in the $\mathrm{Z}$ direction. This is the result of the lowest static stiffness previously noted in this direction (Fig. 7 and 9) and the bending mode of vibrations which corresponds to this frequency (Fig. 12). The vibration amplitude of a lathe with a bolted structure is comparable for the $\mathrm{X}$ and $\mathrm{Y}$ directions. As you can see, much higher static stiffness in the $\mathrm{Y}$ direction does not reduce the amplitude in this direction. For a lathe with a monolithic structure, it can be seen that the vibration amplitude in the $\mathrm{Y}$ direction is slightly higher than in the $\mathrm{X}$ direction. 
9)The summary of the results is presented in Fig. 13 indicates that the use of a monolithic load-bearing structure gives in most cases a significantly higher dynamic stiffness in relation to the bolted one.

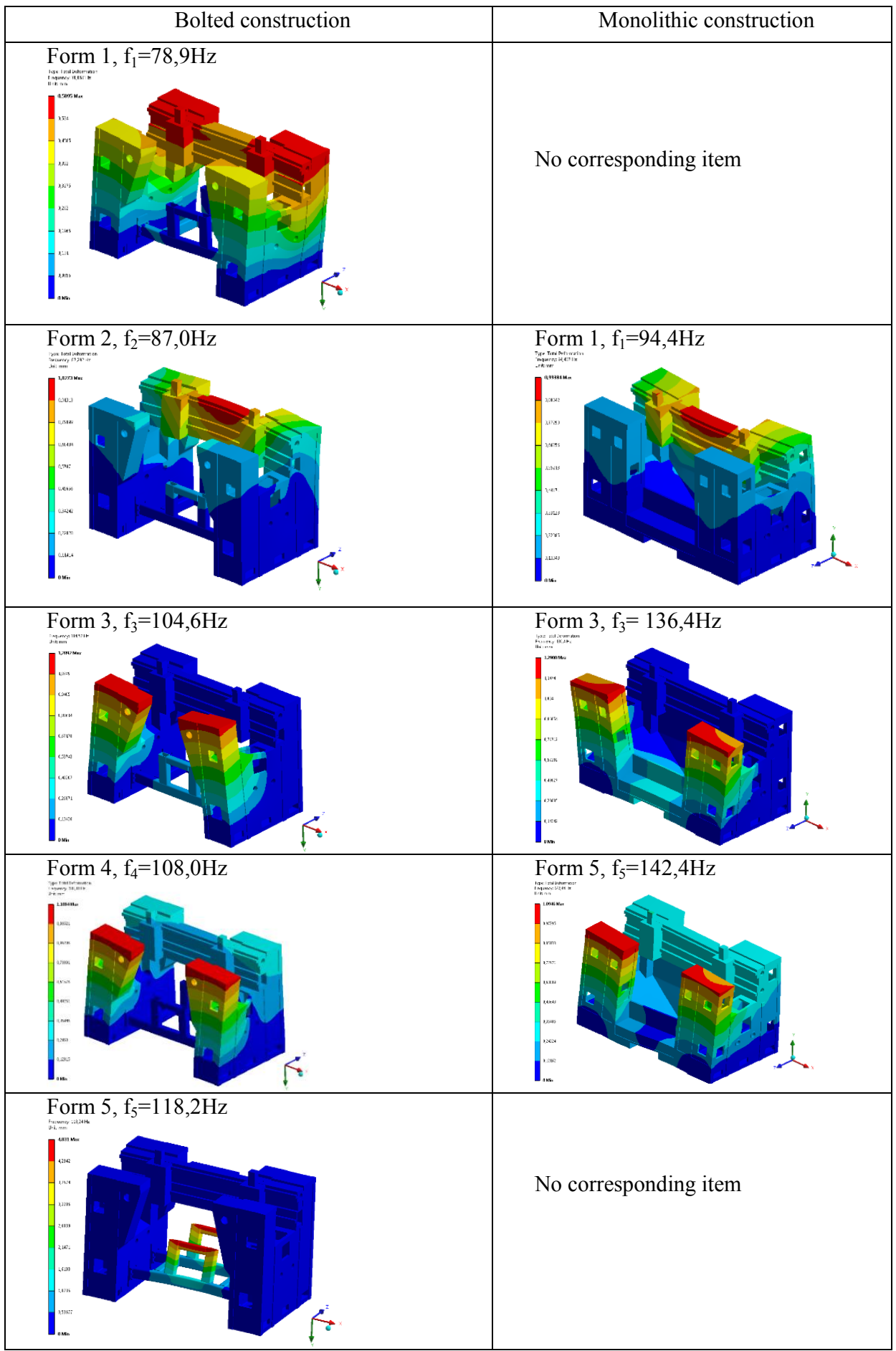




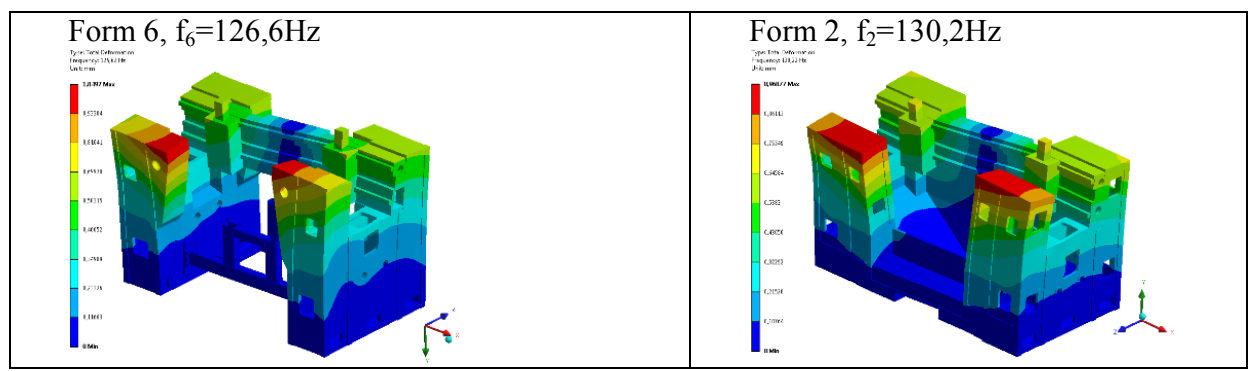

Fig. 11. Comparison of the natural frequencies of a bolted and monolithic support structure for the corresponding vibration modes.

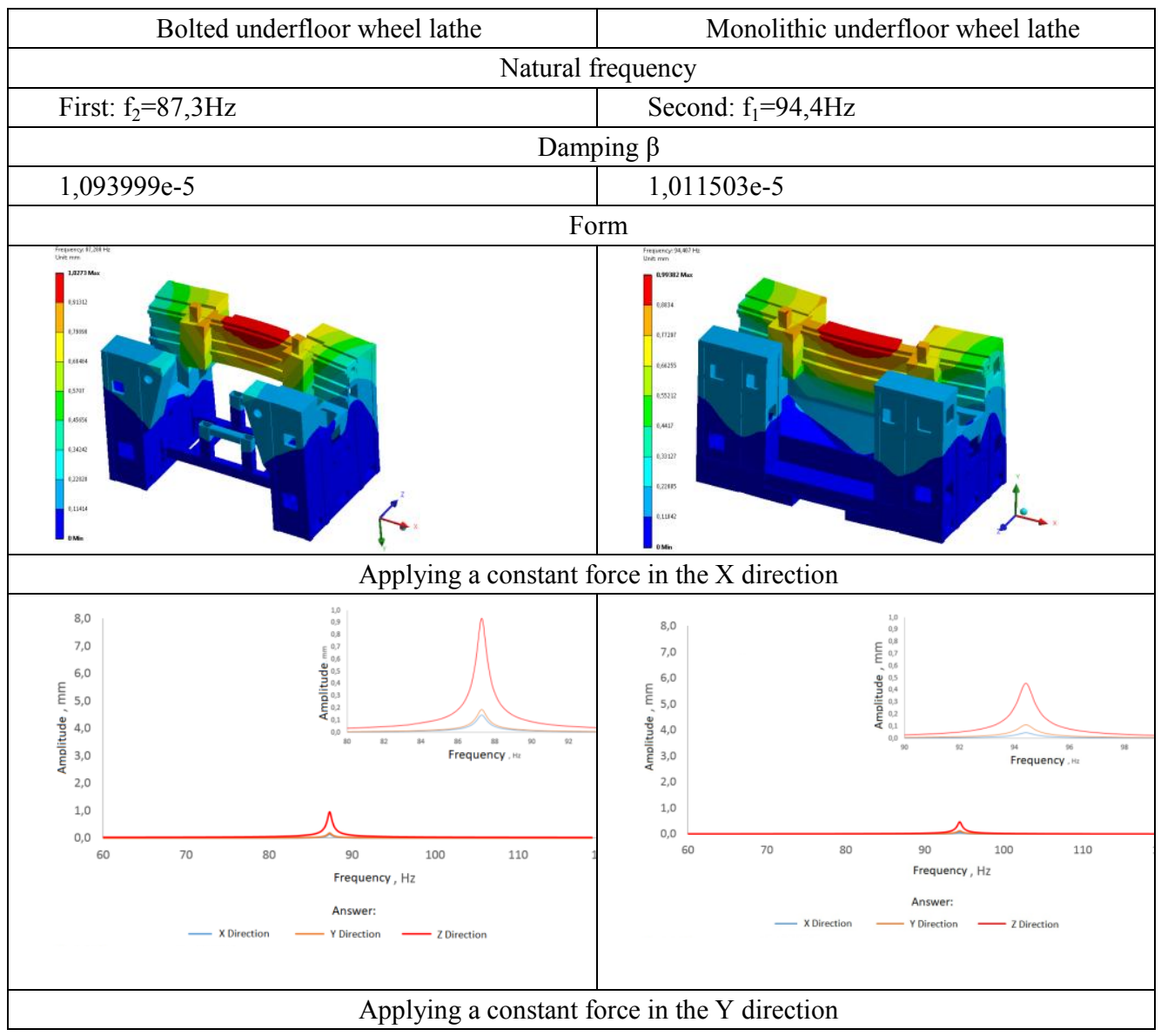




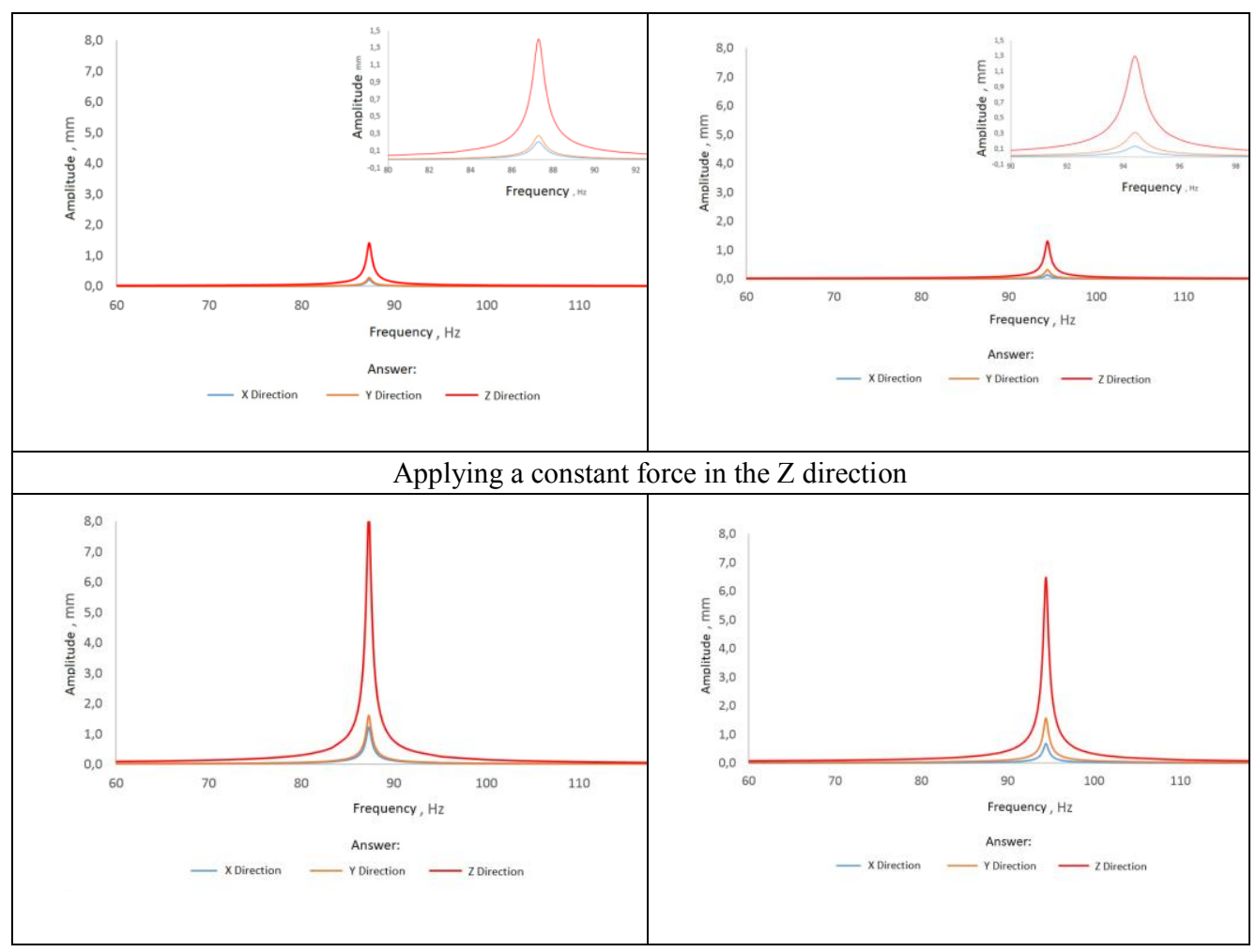

Fig. 12. Response to harmonic excitation for different load directions. 
10) The summary of the results is presented in Fig. 13 indicates that the use of a monolithic load-bearing structure gives in most cases a significantly higher dynamic stiffness in relation to the bolted one.

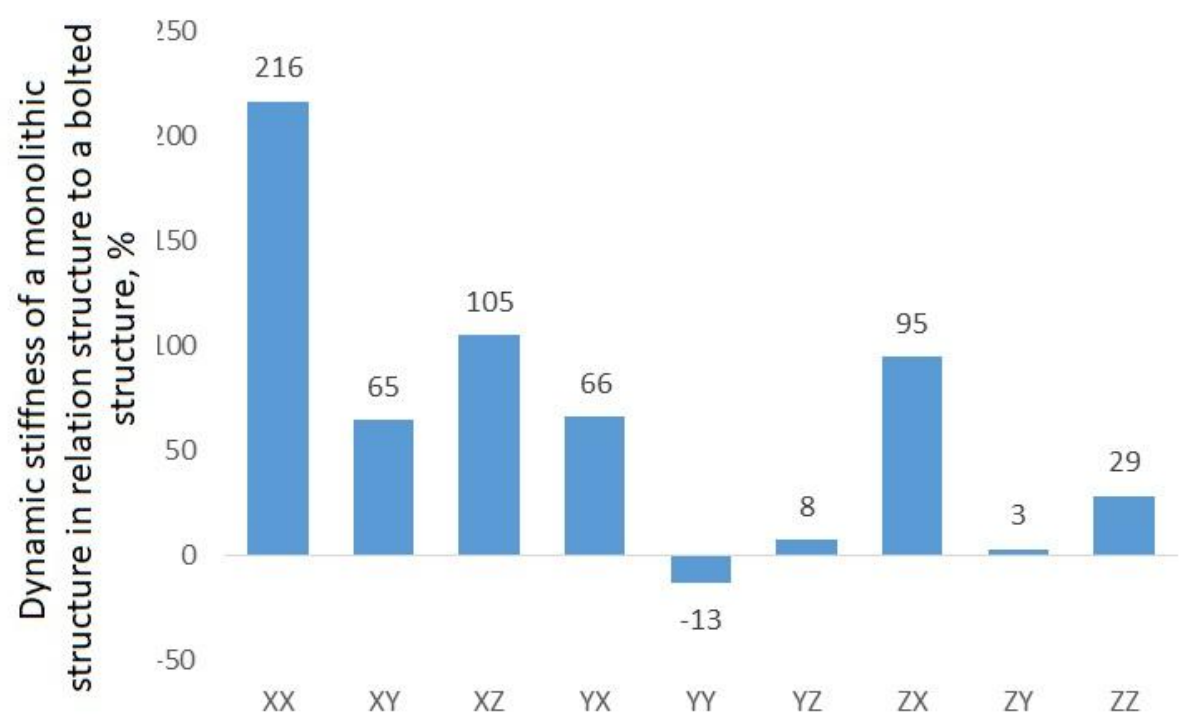

Fig. 13. Percentage change in the dynamic stiffness of the monolithic load-bearing structure compared to the bolted structure (the designation of the columns on the $\mathrm{X}$ axis should be understood as follows, e.g. $\mathrm{XY}$ - means forcing to $\mathrm{X}$ direction and response to $\mathrm{Y}$ direction).

\section{References}

1. K. Lehrich, J. Kosmol Sposoby poprawy właściwości eksploatacyjnych obrabiarek ciężkich. Modelowanie Inżynierskie, 34(65), 64-69 (2017)

2. D. Huo, K. Cheng, F. Wardle Design of a 5-Axis Ultraprecision Micro Milling Machine - Ultra Mill: Part 1: Holistic Design Approach, Design Considerations, and Specifications. The International Journal of Advanced Manufacturing Technology 47, 867-877 (2010)

3. H. Haddad, M. Al Kobaisi Optimization of the polymer concrete used for manufacturing bases for precision tool machines. Composites: Part B, 43, 3061-3068 (2012)

4. J.D. Suh, D.G. Lee Design and manufacture of hybrid polymer concrete bed for highspeed CNC milling machine. Int J Mech Mater Des 4, 113-121 (2008)

5. X. Ping, Y. Ying-hua Research on steel-fibber polymer concrete machine tool structure. JOURNAL OF COAL SCIENCE \& ENGINEERING, 14(4), 689-692 (2008)

6. C. Sung-Kyum, K. Hyun-Jun, C. Seung-Hwan The application of polymer composites to the table-top machine tool components for higher stiffness and reduced weight. Composite Structures, 93, 492-501 (2011)

7. C. Cai, H. Zheng, M. S. Khan, K. C. Hung Modeling of Material Damping Properties in ANSYS. Defense Systems Division, Institute of High Performance Computing 89C Science Park Drive, Singapore Science Park I, Singapore 118261, (2002) 
8. F. Aggogeri, A. Borboni, A. Merlo, N. Pellegrini, R. Ricatto Vibration Damping Analysis of Lightweight Structures in Machine Tools. Materials, 10, 297 (2017)

9. C. Bruni, A. Forcellese, F. Gabrielli, M. Simoncini Hard turning of an alloy steel on a machine tool with a polymer concrete bed. Journal of materials processing technology, 202, 493-499 (2008) 